\title{
Anthós
}

Volume 10 | Issue 1

Article 12

$6-21-2021$

\section{Online Dating Habits amid Covid-19}

Annabelle R. Winking

Portland State University

Follow this and additional works at: https://pdxscholar.library.pdx.edu/anthos

Part of the Social Psychology Commons

Let us know how access to this document benefits you.

\section{Recommended Citation}

Winking, Annabelle R. (2021) "Online Dating Habits amid Covid-19," Anthós: Vol. 10: Iss. 1, Article 12. https://doi.org/10.15760/anthos.2021.10.1.12

This open access Article is distributed under the terms of the Creative Commons Attribution-NonCommercialShareAlike 4.0 International License (CC BY-NC-SA 4.0). All documents in PDXScholar should meet accessibility standards. If we can make this document more accessible to you, contact our team. 


\title{
Online Dating Habits Amid Covid-19
}

\author{
Annabelle R. Winking
}

\section{Introduction}

In recent months, the novel coronavirus (Covid-19) has swept across the globe, causing several countries to impose quarantines and social distancing measures for indeterminate amounts of time. With these measures in place, dating as we know it has changed. Among emerging adults who are active in the dating scene, it is crucial to understand these changes since forming intimate connections has a substantial impact on the mental and physical health of individuals. This study investigates how dating has changed since the enforcement of social distancing due to Covid-19. I focus specifically on Portland residents between 21 and 30 who were using mobile dating apps prior to Covid-19 and who continued to use them during the pandemic.

Since the onset of the Covid-19 pandemic, people have been advised to keep inside and social distance to avoid catching and spreading the novel virus. This, however, has a massive impact on the daily lives of everyone involved. Some of the least discussed consequences are those impacting the dating lives of singles. Although it is often dismissed as trivial, humans are social creatures and the lack of intimate connections can be detrimental to both mental and physical health (Dockterman, 2020). This being said, people are finding ways to maintain contact throughout the pandemic.

Those who do not have a partner or partners are of particular interest since they must find alternatives to meeting potential partners in person. Specifically, adults between the ages of 21 and 30 benefit greatly from intimate relationships and are the most likely to use dating apps (Fetters, 2018; Smith, 2016). Dating apps are a way to safely maintain contact while social distancing, and therefore crucial to both maintaining contact and slowing the spread of Covid-19.

\section{Literature Review}

Dating and developing intimate relationships play an important role in the lives of both emerging adults (approximately ages 18-25) and adults, and can impact both psychological and physiological health (Burman \& Margolin, 1992). As technology advances, however, the methods of dating and forming intimate relationships are rapidly changing. The world is seeing an increase in the use of technology, like dating apps or social media, to seek out and maintain romantic relationships (Antheunis, Valkenburg, \& Peter, 2007). Dating apps are mobile applications designed to generate communication between two people who are interested in relationships such as friendship, casual sex, or romance (Orchard, 2019). These apps feature an individual's personal profile, which often includes photos, a short introduction, and other information such as general location. An

\footnotetext{
${ }^{1}$ This article, which was based on a class project rather than a research study, was not reviewed by
} the PSU IRB. 
algorithm then uses these factors, and others such as gender and sexual orientation to match potential interests. Upon seeing a profile, the user can either express interest, or not. If both parties express interest, then communication becomes available, usually via instant messaging. These apps gained popularity with the release of the first iPhone in 2008 and as of 2019, had 91 million users worldwide (Orchard, 2019). This integration of technology into modern relationships is more important than ever during the pandemic of Covid-19, as the opportunities for meeting others in person have all but disappeared.

Although it is often understated, romantic relationships are fundamental to the well-being of emerging adults and adults. Erik Erickson's seminal stages of psychosocial development show a leading explanation as to why the development of these relationships are fundamental at this particular age (Erickson, 1950). Still used today, Erickson's hypothesis proposes that during emerging adulthood and early adulthood, an individual faces the dilemma of intimacy versus isolation. This dilemma, or stage, suggests that in order to maintain psychological wellbeing, one must be able to form and maintain intimate relationships with others (Erickson, 1950). Contemporary research supports this hypothesis, showing not only that stable and positive relationships are connected with psychological and physiological well-being, but that the impact of these relationships during emerging adulthood is often understated (Burman \& Margolin, 1992; GómezLópez, Viejo, \& Ortega-Ruiz, 2019). There is also evidence of steadily increased oxytocin levels in the brains of young couples who are in love (Schneiderman et al., 2012). High oxytocin levels are related to increased well-being and the successful development of intimate connections (Schneiderman et al., 2012).

Though there is ample evidence showing the importance of forming intimate connections during emerging adulthood, there is little evidence to show the impact of technological development on this process. Studies have been done which show the impact of computer mediated communication (CMC) on interpersonal attraction. CMC refers to any non-face-to-face communication such as texting, calling, or video chatting. The studies done suggest that $\mathrm{CMC}$ enhances both self-disclosure and direct questioning during communication, although text-only seems to be the only method of CMC related to enhanced interpersonal attraction (Antheunis, Valkenburg, \& Peter, 2007). Given the situation of the Covid-19 pandemic, where individuals are advised to social distance and avoid coming into contact with anyone outside the immediate household, CMC is the only safe method to form intimate relationships. Since intimate and romantic relationships can have an impact on the well-being of emerging adults, it is crucial to explore how this population is adapting to dating and forming romantic relationships when face-to-face communication is discouraged. This could alter the nature of $\mathrm{CMC}$ and the formation of intimate relationships among emerging adults, and is fundamental for understanding the 
potential impact $\mathrm{CMC}$ could have on future relationships and both psychological and physiological well-being.

\section{Methods}

I interviewed five Portland singles between the ages of 21-30 who use a variety of dating apps such as Tinder, Grindr, and Hinge. I chose to interview participants as a way to address the complexities of the research question and gain insight from the experiences of my participants (Dunn, 2016). I used semistructured interviews for the purpose of focusing on the research question while allowing the space for the potential diversity of answers and experiences among participants. I employed a research guide, which had several topics to be covered but did not have questions which were worded prior to the interview (Dunn, 2016). I conducted one 30 minute semi-structured interview with each participant.

I chose this particular age group since not only are they the group who use dating apps the most, but are the approximate age of Erik Erikson's stage of intimacy vs. isolation. This stage of psychosocial development implies that emerging adults are seeking success in forming intimate relationships (Smith, 2016; Erickson, 1950). Each of the participants had prior experience with dating apps, and to attempt to account for potential differences in experience, the group included a variety of genders and sexualities. While I sought a diverse group of participants, the sample size (five) was small and therefore is unlikely to be a truly representative sample. All participants remain anonymous and consented to be interviewed, to have recordings of the interviews transcribed, and for excerpts from the transcriptions to be published. Because this research was coursework for the Portland State Honors College course HON201, it did not receive approval from the PSU Institutional Review Board.

As a researcher, I reflected on how my own identity is inseparable from my research (Desmond, 2016). Over the course of my own research, my age, gender, and even sexuality play a role in everything from seeking participants to the information revealed to me in interviews. When seeking information regarding those who use dating apps, my age was helpful in gathering participants, since I am within the age group (21-30) of those who use dating apps the most. This may however leave out crucial differences by individuals out of this age range who also actively use dating apps. After I gathered participants, my age influenced the kind of information I received in interviews. For example, an interviewee of mine spoke openly about non-binary polyamourous relationships, which they may have left out had I been of an older generation.

Another factor that affected my research process is my gender and sexuality. Anecdotally, different genders and sexualities have immensely different experiences on dating apps. For example, my own experience with using dating apps was an inspiration for many of the questions I asked, which may have been 
much different had I been male, or of another sexuality. I chose to interview a range of genders and sexualities to try to account for potential differences, though again someone who is queer may be more open to me (as someone who is female and queer), than if I had been a straight male. This shows just how important one's own identity is in the entire research process, and how it is crucial to reflect on this impact.

\section{Findings and Data Analysis}

To find key themes in the transcriptions of each interview, I used a process of initial and focused color coding. Three essential themes emerged across the interviews which allude to how dating through dating apps has changed since the onset of Covid-19: social distancing did not hinder the desire to form intimate connections, the idea of socially distant dating was interesting though many gave up after an attempt, and though people still met up, there was guilt around the experience.

The first theme that emerged was that enforced social distancing did not seem to change the desire to form intimate connections. Four out of the five participants expressed this desire when asked whether forming intimate connections was an important part of their life at the moment. These responses consisted of "It sounds like something that would make my life happier. It sounds like something I want, but at my current situation it's so unattainable", "Yeah I think so, um I think there's definitely an aspect of just wanting to, like - no, yeah I think definitely", "Hmm. I mean it'd be a goal of mine", and simply "absolutely." After this was established, the participants were asked if the quarantine had changed this desire, to which those who initially expressed the desire said it did not. For example, K (pseudonym) expressed "...But there's always that aspect of a relationship, of a romantic relationship that you want, and you know, I think even with quarantine and Covid, it's still there, it didn't go anywhere." This theme is fundamental in understanding the other themes which emerged later in the interviews.

A second theme which emerged was that participants were interested in socially distanced dating, although those who attempted it eventually gave it up and resumed pre-Covid 19 contact. Socially distanced dating is any form of date where social distancing guidelines are maintained. Apps such as Hinge and Tinder have modified their applications to suggest and include video chat as a potential dating option. One example of this is $\mathrm{K}$, who explained their attempt at social distance dating where they "met up with somebody from a dating app on Mt. Tabor and we sat six feet apart. Uh, I think we hung out like three times socially distanced?" When I asked if they continued to date from a safe distance, they responded that after the three dates they "did not socially distance after that." 
Here, they are implying that they continued to date this person but no longer socially distanced. The two other interviewees who attempted a socially distanced date (a form of CMC) such as a video chat or a park date also quickly gave up on this. For example, A (pseudonym) admitted that "Ima be honest, I have met with someone, I met [in person] with one of the people that I've talked to. But, I-it's kind of been continuous but I try not to meet with them as much because of Covid." This suggests that despite the interest and awareness of socially distant dating, dating itself hasn't changed much. Change was seen, however, in the attitudes around dating, in particular when participants met others in person.

A third theme which emerged across the interviews is that interviewees felt guilt about meeting up with people during the mandatory quarantine. This suggests that although the interviewees' dating habits didn't change entirely, the mentality may have been altered. In the previous paragraph, A was hesitant to admit that they had met up with someone in person, which implies that they felt some amount of guilt or reservations around this subject. S (pseudonym) expresses the guilt they feel after having met up with the person they had been seeing:

I think it's hard to say, and it's like no matter what choices you make, you could feel guilty about. Like even just seeing you right now in my yard, maybe some people might say that wasn't [indistinguishable]. You know, so, like, it's hard to choose. And I - I've been seeing my closest friends and it's like I think that - and then I have some guilt about that! But then it's also like you kind of have to weigh your mental health with, like... [very long pause] within reason.

$\mathrm{K}$ also expressed a similar attitude, as well as addressing the hypocrisy around feeling guilt while still meeting up with their partner:

Well I think getting back to what you're saying about the greater good, I mean that question is so hard to answer because, like, on a personal level you're like-you don't feel like a bad guy, you know, if you do go meet up with somebody_nobody's gonna, like, you don't wanna be the bad guy but then if somebody tells you they're doing that, then you're like "ugh you shouldn't be meeting up with random people!" But it's ok if I do it, and that just makes you feel kind of weird.

These passages suggest that this age group was cognizant of the risk posed by meeting new people in-person but again, did not ultimately change their habits. 
Although these themes suggest how attitudes toward dating among emerging adults have changed since the onset of enforced social distancing due to the Covid-19 pandemic, the habits themselves appear unchanged. This is particularly interesting since this could have consequences for both the spread of the virus as well as the mental health of single emerging adults. Since dating habits appear to remain unchanged, this suggests that individuals are not entirely complying with social distancing guidelines which increase the individual's risk of both contracting and spreading Covid-19. As previously mentioned, forming intimate relationships is a significant factor in the well-being of emerging adults, and the guilt and anxiety which could accompany in-person dating may have an impact on the ability to successfully form new intimate relationships (GómezLópez, Viejo, \& Ortega-Ruiz, 2019). This could potentially have lasting consequences on attitudes around dating in this age group.

\section{Limitations and Future Directions}

There are a few notable limitations to this study, notably the sample size and the ongoing nature of the Covid-19 pandemic. These limitations, however, are indicators as to where future research could and should lead. The sample size, five, is small and therefore may not accurately depict the diversity of those who use dating apps and are dating amid the pandemic. This suggests that future studies should use a larger sample size to see if the themes which emerged are representative of the population.

A second limitation is that the Covid-19 pandemic is ongoing, and therefore dynamic. This study was done within the first two months of enforced social distancing, and therefore may have only captured potential trends from the beginning of the quarantine. This suggests that future longitudinal studies could be done to capture the dynamic nature of dating as the pandemic persists. This could identify potential trends or changes in dating over the course of the pandemic. It has been suggested that the pandemic will have a permanent impact on the lives of all individuals, and it is important to identify how dating has changed, and if this change will persist past the end of enforced social distancing. This is essential for emerging adults, who are having to find new ways to form intimate connections.

\section{Conclusion}

Forming successful intimate connections is fundamental for both psychological and physiological health, especially among emerging adults. In times when social isolation has been normalized and previous habits become unavailable, such as during mandatory social distancing, it is important to identify how individuals are adapting to forming new intimate connections. This research suggests that during the first three months of Covid-19, Portland residents aged 
21-30 still felt the desire to seek intimate connections and did so in quarantine by social distance dating or meeting up in person. There was, however, a collective guilt felt for breaking social distancing mandates. Although dating habits seem to have not changed dramatically, the potential rise in guilt and anxiety may have implications on the future of dating. This guilt could become a common obstacle in the formation of new intimate connections which may be an unanticipated challenge in the lives of emerging adults post-Covid. These themes are essential in understanding potential consequences of the pandemic on modern dating. This suggests how single individuals might be coping with the social isolation created by the pandemic, which is fundamental to understanding the inevitable and permanent changes brought on by the Covid-19 pandemic.

\section{References}

Antheunis, M. L., Valkenburg, P. M., \& Peter, J. (2007). Computer-Mediated Communication and Interpersonal Attraction: An Experimental Test of Two Explanatory Hypotheses. CyberPsychology \& Behavior, 10 (6), 831836. doi: 10.1089/cpb.2007.9945

Burman, B., \& Margolin, G. (1992). Analysis of the Association Between Marital Relationships and Health Problems: An Interactional Perspective. Psychological Bulletin, 12(1), 39-63. doi: 10.1037/0033-2909.112.1.39

Coronavirus Disease 2019 (COVID-19). (2020, April 17). Retrieved April 19, 2020, from https://www.cdc.gov/coronavirus/2019-ncov/index.html

Desmond, M. (2016). About this Project. In M. Desmond (Author), Evicted: Poverty and profit in the American city (pp. 316-336). New York, NY: Crown.

Dockterman, E. (2020, April 11). The Coronavirus Is Changing How We Date. Experts Think the Shifts May Be Permanent. TIME . Retrieved from https://time.com/5819187/dating-coronavirus/

Dunn, K. (2016). Interviewing. In I. Hay (Ed.), Qualitative Research Methods in Human Geography (pp. 149-171). Don Mills, Ontario, Canada: Oxford University Press.

Erikson, E. H. (1950). Childhood and society. New York: W W Norton \& Co.

Fetters, A. (2018, December 21). The Five Years That Changed Dating. The Atlantic. Retrieved from https://www.theatlantic.com/family/archive/2018/12/tinder-changeddating/578698/

Gómez-López, M., Viejo, C., \& Ortega-Ruiz, R. (2019). Well-Being and Romantic Relationships: A Systematic Review in Adolescence and Emerging Adulthood. International Journal of Environmental Research and Public Health, 16 (13), 2415. doi: 10.3390/ijerph16132415 
Orchard, T. (2019). Dating Apps. Encyclopedia of Sexuality and Gender, 1-3. doi:10.1007/978-3-319-59531-3 19-1

Schneiderman, I., Zagoory-Sharon, O., Leckman, J. F., \& Feldman, R. (2012). Oxytocin during the initial stages of romantic attachment: Relations to couples' interactive reciprocity. Psychoneuroendocrinology, 37 (8), 12771285. doi: 10.1016/j.psyneuen.2011.12.021

Smith, A. (2016, February 11). 15\% of American adults use online dating sites or mobile apps. Retrieved April 19, 2020, from

https://www.pewresearch.org/internet/2016/02/11/15-percent-of-americanadults-have-used-online-dating-sites-or-mobile-dating-apps/ 